\title{
Understanding Current Attitudes to HER2 Testing for Breast Cancer at Tertiary Referral Hospitals of Metro Manila, Philippines
}

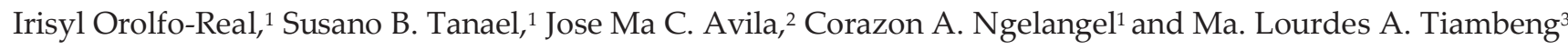 \\ ${ }^{1}$ Section of Medical Oncology, Department of Medicine, College of Medicine and Philippine General Hospital, University of the Philippines Manila \\ ${ }^{2}$ Department of Pathology, College of Medicine, University of the Philippines Manila \\ ${ }^{3}$ Department of Medicine, Cardinal Santos Medical Center, Mandaluyong City
}

\begin{abstract}
Introduction. The difficulty of obtaining accurate and reproducible assessment of HER2 status in the Philippines, despite the predictive value of the test for HER2 positive breast cancer patients, may be sufficiently addressed if an effective multidisciplinary approach to HER2 testing is carried out. This may be accomplished by identifying disparities and similarities in HER2 testing for breast cancer.
\end{abstract}

Methods. This is a cross-sectional study which included medical oncologists who had used trastuzumab for HER2-positive patients. Surgeons, who belonged to the same tertiary hospital as the medical oncologists were also interviewed. The survey questionnaires were administered via face-to-face, mail, or fax. Responses were kept confidential. Questionnaire responses were analysed using summary statistics.

Results. There were 35 medical oncologists and 37 surgeons 93\% stated that all women diagnosed with breast cancer should be tested for HER2 at the point of diagnosis; $61 \%$ stated that the greatest barrier to initiating HER2 testing was inadequate patient funds. $57 \%$ medical oncologists and $65 \%$ surgeons believed that HER2 testing for all breast cancer patients at the point of clinical diagnosis was being observed at their hospital. $69 \%$ stated that medical oncologists or surgeons should request for HER2 test whoever saw the patients first; $59 \%$ stated that whoever saw the patient first provide the patient information about HER2 testing whereas $28 \%$ stated it is the medical oncologist who should provide information about HER2 testing. $47 \%$ medical oncologist and $63 \%$ surgeons stated that surgeons should arrange for breast tissue sample collection; $27 \%$ medical oncologists and $20 \%$ surgeons stated that pathologists should do this.

Presented at the Round Asia Oncology Forum, September 2010, Bali, Indonesia.

Corresponding author: Corazon A. Ngelangel, MD, MS, PhD

Section of Medical Oncology

Department of Medicine

Philippine General Hospital

University of the Philippines Manila

Taft Avenue, Ermita, Manila 1000 Philippines

Tele/Fax: +6325263775

Email: corazon.ngelangel@gmail.com
Conclusion. Medical oncologists and surgeons were similar in the opinion that all women diagnosed with breast cancer should be tested for HER2 at the point of diagnosis, financial capability was the greatest barrier for initiating HER2 testing, and whoever saw the patient first should provide patient education. There was disparity on who should request first and who should arrange for tissue collection.

Key Words: HER2neu test, multidisciplinary team approach, breast cancer

\section{Introduction}

Human epidermal growth factor receptor-2 (HER2) over-expression is estimated to occur in $20-25 \%$ of breast cancer patients. It is an established prognostic factor with the tumor being more aggressive resulting to decreased survival. Its presence is a good predictor of response to antiHER2 therapy including trastuzumab and lapatinib. ${ }^{1-3}$ The adjuvant use of trastuzumab can significantly decrease the risk of recurrence by $46-58 \%$ and improve overall survival. In the metastatic setting, both trastuzumab and lapatinib significantly prolonged time to progression. ${ }^{4}$

The determination of HER2 overexpression at point of diagnosis for all primary breast cancers is recommended in current practice guidelines to optimize management of these patients. ${ }^{1-4}$ However, studies have shown that HER2 testing is inaccurate in $20 \%$ of cases. ${ }^{3-7}$ Extra-analytical processes such as ordering of the test, handling of specimen, appropriate interpretation, and reaction to the results are potential sources of error just like in any diagnostic test. Neither of the two tests available, immunohistochemistry (IHC) and in-situ hybridization (FISH/CISH), can be considered as the standard. Studies showed suboptimal concordance between local versus central HER2 testing. 2,3,7,8 The current cost of the test, its potential benefits, its implications and demands on the treatment put pressure on ensuring the accuracy of the diagnostic test.

These concerns have been addressed by guidelines developed by oncologists and pathologists with the purpose of delivering accurate results and appropriate treatment. 3,4 The prognostic and predictive utility of HER2 test along with the measures being taken to ensure its diagnostic accuracy must be communicated well to the end user of all these information, the breast cancer patient. This requires 
the involvement of each member of the multidisciplinary team. Effective communication and interaction of the surgeon with other health care professionals involved in the diagnosis, staging, and treating cancer patients reduce time to diagnosis, provide prompt appropriate treatment, and improve patient satisfaction. . $^{9-11}$

In a study ${ }^{1}$ done in UK after the 2005 directive of the health department on HER2 testing of breast cancer patients at point of diagnosis, there was note of general acceptability (90\%) of the concept among oncologists and pathologists. The acceptability of the recommendation by the breast care specialists in a developing country is a growing concern. The above mentioned challenges being faced by HER2 testing can be more palpable in a country like the Philippines. Currently, the laboratories try to implement the guidelines set by the American Society of Clinical Oncology/College of American Pathologists (ASCO/CAP). ${ }^{3}$ However, there is no existing local central body or guidelines to ensure accuracy and concordance of HER2 results. These and many other issues on HER2 testing may be sufficiently addressed if effective multidisciplinary approach is carried out.

This study explores the understanding and current practice of Philippine medical oncologists and surgeons with regard to HER2 testing, and determines if similarity exists and where disparity is regarding initiation of HER2 testing.

\section{Methods}

This is a cross-sectional study among medical oncologists who had used anti-HER2 therapy in their practice, identified through interviews. Surgeons who belonged to the same hospital as the medical oncologists and had used anti-HER2 therapy for HER2 positive patients were also included.

A survey questionnaire was developed with the aid of the information from the UK consensus study by Dowsett et $\mathrm{al}^{1}$ (Appendix). A pilot testing was done by administering the questionnaire to some medical oncologists and surgeons who were not included as subjects of the study. Revisions were done as appropriate. The survey questionnaires were distributed to the respondents and collected via mail, fax, or in person. Informed consent was taken. The respondent had a right not to answer the questionnaire. The questionnaire did not contain the name of the respondent to maintain confidentiality. The answers were classified as to the specialty of the respondent. This was done to facilitate the comparisons to be made between medical oncologists and surgeons. Questionnaire responses were analysed for the entire group using summary statistics.

\section{Results}

There were 35 medical oncologists and 37 surgeons who responded (Table 1). There were slightly more female medical oncologists (57\%), whereas $62 \%$ of the surgeons were male. More than half of the medical oncologists were aged 40-49 years whereas 43\% surgeons were aged 30-39 years. Majority had their main practice setting in a tertiary hospital in Metro Manila (MM).

Table 1. Demographic profile

\begin{tabular}{|c|c|c|c|}
\hline & $\begin{array}{c}\text { Medical } \\
\text { Oncologists } \\
\text { Number }(\%)\end{array}$ & $\begin{array}{c}\text { Surgeons } \\
\text { Number (\%) }\end{array}$ & $\begin{array}{c}\text { Total } \\
\text { Number }(\%)\end{array}$ \\
\hline \multicolumn{4}{|l|}{ Sex } \\
\hline Male & $15(43 \%)$ & $23(62 \%)$ & $38(53 \%)$ \\
\hline Female & $20(57 \%)$ & $14(38 \%)$ & $34(47 \%)$ \\
\hline \multicolumn{4}{|l|}{ Age } \\
\hline $30-39$ & $8(23 \%)$ & $16(43 \%)$ & $24(33 \%)$ \\
\hline $40-49$ & $19(54 \%)$ & $8(22 \%)$ & $27(37.5 \%)$ \\
\hline $50-59$ & $7(20 \%)$ & $8(22 \%)$ & $15(21 \%)$ \\
\hline 60 years and above & $1(3 \%)$ & $5(13 \%)$ & $6(8 \%)$ \\
\hline \multicolumn{4}{|l|}{ Main clinical practice setting } \\
\hline Tertiary hospital, MM & $31(88 \%)$ & $33(89 \%)$ & $64(88 \%)$ \\
\hline $\begin{array}{l}\text { Tertiary hospital, MM / } \\
\text { outside MM }\end{array}$ & $2(6 \%)$ & $3(8 \%)$ & $5(7 \%)$ \\
\hline Secondary hospital, MM & 0 & $1(3 \%)$ & $1(1.4 \%)$ \\
\hline Others & $1(3 \%)$ & 0 & $1(1.4 \%)$ \\
\hline Not specified & $1(3 \%)$ & 0 & $1(1.4 \%)$ \\
\hline
\end{tabular}

Breast cancer cases constitute $26-50 \%$ of the cancer cases seen by $47 \%$ of the respondents (Figure 1 ). More than half of the medical oncologists and likewise surgeons requested HER2 test in $>75 \%$ of their breast cancer patients.

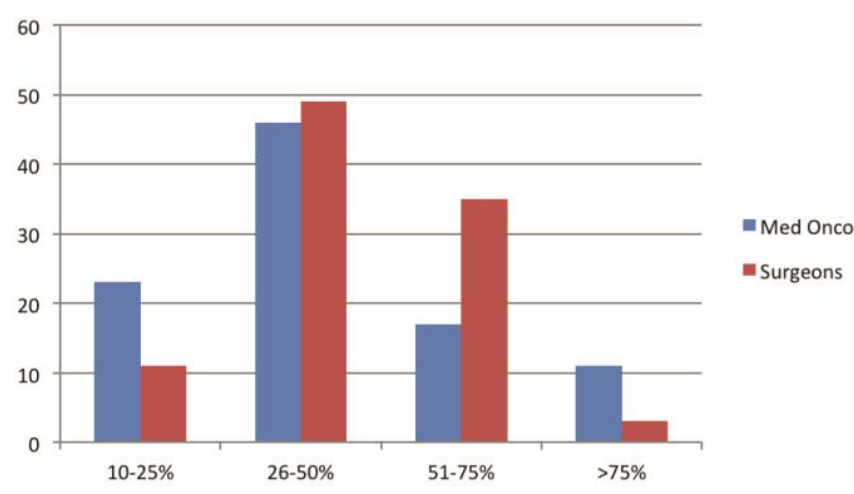

Figure 1. Breast cancer patients being treated per month

Most medical oncologists requested HER2 IHC tests from the National Kidney and Transplant Institute (NKTI). Half of the surgeons sent their requests to St. Luke's Medical Center (SLMC) and The Medical City (TMC).

For HER2 FISH requests, $>60 \%$ of medical oncologists sent to NKTI while $50 \%$ surgeons sent their requests to SLMC.

\section{HER2 Test at Point of Diagnosis}

Majority believed that HER2 must be tested for all women with breast cancer at point of diagnosis (Table 2). One medical oncologist who stated that HER 2 should not be tested at point of diagnosis reasoned that it be must be done on the basis of the type of carcinoma. The other two stated 
that it must be based on the capacity of the patient to undergo HER2 targeted systemic therapy. One of the two surgeons who answered no to the same question said that breast mass with size $<1 \mathrm{~cm}$ does not need HER2 testing.

Table 2. Testing HER2 at point of diagnosis

\begin{tabular}{lcc}
\hline \multirow{1}{*}{ Specialty } & \multicolumn{2}{c}{ Test HER2 at point of diagnosis } \\
\cline { 2 - 3 } & Yes & No \\
\hline Medical Oncologist & 32 & 3 \\
Surgeon & 35 & 2 \\
Total & 67 & 5 \\
\hline
\end{tabular}

Many (61\%) believed that at their hospital, HER2 was requested for all patients at point of diagnosis (Figure 2); $29 \%$ requested HER2 only if the patient had the financial capability for the test; $4 \%$ requested only after failure of chemotherapy and/or hormone therapy with the patient being more likely to receive trastuzumab. One medical oncologist thought that medical oncologists requested HER2 test only when surgeons failed to request. One surgeon commented that majority were aware but few specialists requested HER2.

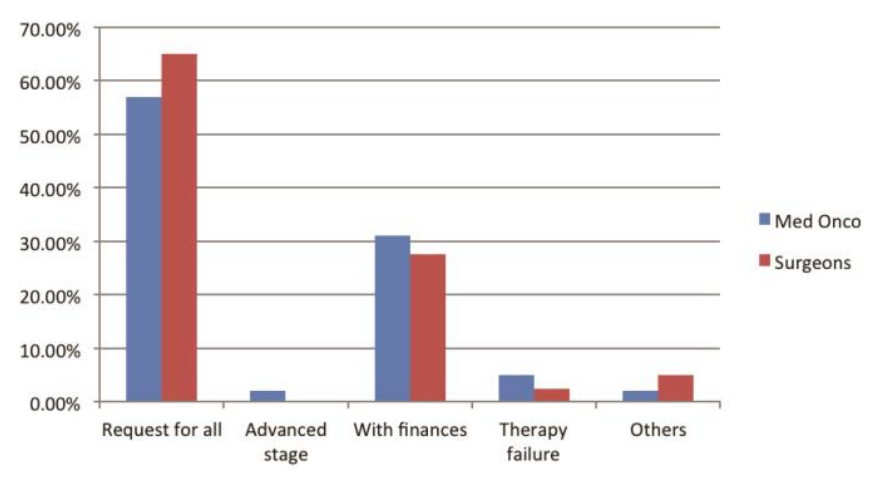

Figure 2. Practice of HER2 testing at the hospital

\section{Barriers to HER2 Testing}

Majority (61\%) stated that the greatest barrier in initiating HER2 testing in their hospital was the inadequacy of patient funds (Figure 3); 32\% medical oncologists and $36 \%$ surgeons indicated that shortfall of adequate expertise/experience, absence of local and central laboratory services, inadequate quality control and assurance posed as barriers to initiating HER2 testing.

\section{Informational Roles and Logistics for HER2 Testing}

Sixty-nine percent $(69 \%)$ stated that the medical oncologist or the surgeon, whoever saw the patient first, must request for HER2 test (Table 3). A fifth of the surgeons stated that requesting for HER2 test was their primary responsibility.

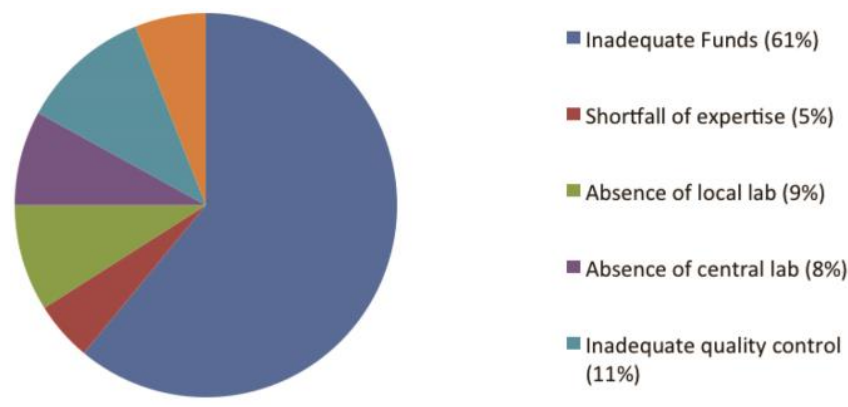

Figure 3. Barriers to initiating HER2 testing

Table 3. Who should request for HER2 testing

\begin{tabular}{lrrr}
\hline & $\begin{array}{c}\text { Medical } \\
\text { Oncologists }\end{array}$ & Surgeons & Total \\
\hline Medical oncologist & $5(12 \%)$ & $5(12 \%)$ & $10(12 \%)$ \\
Surgeon & $3(7 \%)$ & $8(19 \%)$ & $11(13 \%)$ \\
Med oncologist or surgeon, & $30(71 \%)$ & $28(67 \%)$ & $58(69 \%)$ \\
$\quad$ whoever saw patient first & & 0 & $3(4 \%)$ \\
Pathologist & $3(7 \%)$ & 0 & $1(1 \%)$ \\
Patient & $1(2 \%)$ & $1(2 \%)$ & $1(1 \%)$ \\
Not specified & 0 & & \\
\hline
\end{tabular}

Fifty-four percent (54\%) stated that the surgeons must be the one to arrange for breast tissue sample collection (Table 4). Twenty-seven percent (27\%) medical oncologists, however, thought that the pathologist should do this. Twenty percent (20\%) surgeons also thought that pathologists should do this.

Table 4. Who should arrange for breast tissue sample collection

\begin{tabular}{lrrr}
\hline & $\begin{array}{c}\text { Medical } \\
\text { Oncologists }\end{array}$ & Surgeons & Total \\
\hline Medical oncologist & 0 & $1(2 \%)$ & $1(1 \%)$ \\
Surgeon & $23(47 \%)$ & $26(63 \%)$ & $49(54 \%)$ \\
Staff at operating theatre & $8(16 \%)$ & $4(10 \%)$ & $12(13 \%)$ \\
Pathologist & $13(27 \%)$ & $8(20 \%)$ & $21(23 \%)$ \\
Medical technician of & $4(8 \%)$ & $2(5 \%)$ & $6(7 \%)$ \\
$\quad$ histopathology lab & $1(2 \%)$ & & \\
Others, whoever is in charge & & 0 & $1(1 \%)$ \\
\hline
\end{tabular}

Fifty-nine percent (59\%) stated that whoever saw the patient first should provide information about HER2 testing (Table 5). Thirty-five percent (35\%) medical oncologists stated that it is the medical oncologist who should be providing information on HER2 testing. Twenty-two percent $(22 \%)$ surgeons stated that medical oncologists should primarily provide the patients information on HER2 testing. 
Table 5. Who should provide patients information about HER2 testing

\begin{tabular}{lrrr}
\hline & $\begin{array}{c}\text { Medical } \\
\text { Oncologists }\end{array}$ & Surgeons & \multicolumn{1}{c}{ Total } \\
\hline Medical oncologist & $14(35 \%)$ & $10(22 \%)$ & $24(28 \%)$ \\
$\begin{array}{l}\text { Surgeon } \\
\text { Med oncologist or surgeon, }\end{array}$ & $3(7.5 \%)$ & $6(13 \%)$ & $9(11 \%)$ \\
$\quad 22(55 \%)$ & $28(62 \%)$ & $50(59 \%)$ \\
$\quad$ whoever sees patient first & $1(2.5 \%)$ & 0 & $1(1 \%)$ \\
$\begin{array}{c}\text { Nurses } \\
\begin{array}{c}\text { Others, any oncologist or } \\
\text { practicing physician }\end{array}\end{array}$ & 0 & $1(2 \%)$ & $1(1 \%)$ \\
\hline
\end{tabular}

\section{Discussion}

Medical oncologists and surgeons both agreed with the recommendation in practice guidelines to request for HER2 at point of diagnosis for all breast cancer patients. Majority of them stated such practice was being done in their institutions. However, a quarter stated that their colleagues only requested for HER2 depending on the financial capability of the patients. The patients for whom HER2 test were requested were also those who were likely to receive trastuzumab if prescribed to. Despite the robust evidence in randomized trials on the predictive and prognostic benefit of the test for those who are HER2 positive, limitation in funds poses a real challenge to the compliance to this recommendation.

An important barrier to initiating HER2 testing involves the availability and quality standardization of the HER2 tests. The shortfall of adequate expertise/experience, absence of local lab services, absence of central lab services, and inadequate quality control and assurance discourage a number of clinicians in initiating the test. In the UK study ${ }^{1}$, there was a consensus to ensure the high quality of HER2 tests. It is recommended that laboratories must be accredited, participate in the national external quality assessment scheme, and be audited annually. There is a need for quality control procedures to avoid discordance in interpretation even for experienced laboratories. ${ }^{2,8}$

Arranging for breast tissue sample collection is part of pre-analytic step in histopathology. The specimen must be accompanied by the request with relevant and adequate clinical details. The name and contact information of the clinician must be provided to help in obtaining additional clinical information. In this way, the diagnostic process is facilitated and delay in reporting is avoided. ${ }^{9}$

Many clinicians believed that the surgeon and staff at the operating theatre were responsible for arranging for the breast tissue sample specimen; a fourth saw the pathologists to be playing an important role in arranging for the specimen. This discrepancy is important to recognize. Common pre-analytic errors include: patient misidentification, specimen mislabelled or unlabelled, incorrect or compromised specimen, inappropriate specimen transport conditions, specimen processed incorrectly, specimen stored inappropriately before testing, and wrong test(s) ordered. Patient preparation, ordering of the test and breast tissue sample collection is carried out by the clinicians, whereas processing of specimen is primarily the work of pathologists. Thus, as early as the pre-analytic aspect of HER2 testing, the multidisciplinary approach must already be at work.

The primary responsibility of requesting for HER2 lies on the medical oncologist or surgeon who first saw the patient. A number of surgeons however, stated that the responsibility was primarily theirs, maybe because most patients with palpable breast mass consult with them first. A few medical oncologists thought that pathologists also had a role in requesting HER2 test. The medical oncologists must have expected that pathologists will do routine HER2 testing for all breast tissue samples since this is already part of the recommendations.

More than half of the specialists stated that the medical oncologist or surgeon whoever saw the patient first has the responsibility to provide information to the patients regarding HER2 test. A third of medical oncologists saw themselves to be primarily responsible in providing the information. A fourth of the surgeons agreed that it was the medical oncologist's responsibility to provide this information. Some surgeons may state that though they were the ones who primarily request for HER2 testing because they usually see the patients first, further information and clarification about the test must be provided by medical oncologists. This may reflect an increasing recognition of the importance of a multidisciplinary team in breast cancer care.

Many similarities existed between the opinions of surgeons and medical oncologists regarding HER2 testing. Disparity existed on matters involving informational roles and logistics of HER2 testing. Though the differences were minor, these may reveal a lack of interdisciplinary awareness. Awareness of one's roles and the roles of other members in the multidisciplinary team will help in promoting effective multidisciplinary approach to patient care. Aside from the benefit it gives to patients, it will also allow the individual team members to be efficient leading to increased morale and work satisfaction. ${ }^{11}$

It is recommended that a campaign for compliance to international accepted guidelines on HER2neu test be done among the pertinent medical community and then a followup survey be done to evaluate the impact. Almost all the respondents in this study came from tertiary hospitals in Metro Manila and may not reflect the practice in other hospitals especially those which are community-based.

\section{Summary}

Medical oncologists and surgeons were similar in the opinion that all women diagnosed with breast cancer should be tested for HER2 at the point of diagnosis. There was a general agreement with the current recommendation on 
initiation of HER2 testing. However, financial capability was viewed as the greatest barrier for initiating HER2 testing in the Philippine healthcare setting. The specialists also agreed that whoever sees the patient first should provide patient education. Disparity existed on who should request first and who should arrange for tissue collection which may reflect a need for strengthening of the multidisciplinary care team approach.

\section{References}

1. Dowsett M, Hanby AM, Laing R, Walker R. for the National HER2 Consultation Steering Group. HER2 testing in the UK: consensus from a national consultation. J Clin Pathol. 2007; 60(6):685-9.

2. Sauter G, Lee J, Bartlett JM, Slamon DJ, Press MF. Guidelines for human epidermal growth factor receptor 2 testing: biologic and methodologic considerations. J Clin Oncol. 2009; 27(8):1323-33.

3. Wolff AC, Hammond ME, Schwartz JN, et al. American Society of Clinical Oncology/College of American Pathologists guideline recommendations for human epidermal growth factor receptor 2 testing in breast cancer. J Clin Oncol. 2007; 25(1):118-45.
4. NCCN. NCCN Clinical Practice Guidelines: Breast Cancer [Online]. v.3.2010 [cited 2010 June]. Available from www.nccn.org.

5. Paik S, Bryant J, Tan-Chiu E, et al. Real-world performance of HER2 testing-National Surgical Adjuvant Breast and Bowel Project experience. J Natl Cancer Inst. 2002; 94(11):852-4.

6. Roche PC, Suman VJ, Jenkins RB, et al. Concordance between local and central laboratory HER2 testing in the breast intergroup trial N9831. J Natl Cancer Inst. 2002; 94(11):855-7.

7. Lippi G, Banfi G, Buttarello M, et al. Recommendations for detection and management of unsuitable samples in clinical laboratories. Clin Chem Lab Med. 2007; 45(6):728-36.

8. Dowsett M, Hanna WM, Kockx M, et al. Standardization of HER2 testing: results of an international proficiency-testing ring study. Mod Pathol. 2007; 20(5):584-91.

9. Sharif MA, Mushtaq S, Mamoon N, et al. Clinician's responsibility in pre-analytical quality assurance of histopathology. Pak J Med Sci. 2007; (Part-I) 23(5):720-3.

10. Gagliardi AR, Wright FC, Davis D, McLeod RS, Urbach DR. Challenges in multidisciplinary cancer care among general surgeons in Canada. BMC Med Inform Decis Mak. 2008; 8:59.

11. Jenkins VA, Fallowfield LJ, Poole K. Are members of multidisciplinary teams in breast cancer aware of each other's informational roles? Qual Health Care. 2001; 10(2):70-5.

Appendix. Survey questionnaire

\section{CHALLENGES ON MULTIDISCIPLINARY APPROACH TO HER2 TESTING}

Please check the box corresponding to your answer:

\section{About you}

Sex

male

female

Age

$$
\begin{aligned}
& \square \text { 20-29 } \\
& \square \text { 30-39 } \\
& \square \text { 40-49 } \\
& \square \text { 50-59 } \\
& \square 60+
\end{aligned}
$$

\section{Main Clinical Practice Setting}

$$
\begin{aligned}
& \square \text { tertiary hospital, Metro Manila } \\
& \square \text { tertiary hospital, outside Metro Manila } \\
& \square \text { secondary hospital, Metro Manila } \\
& \square \text { secondary hospital, outside Metro Manila } \\
& \square \text { others }
\end{aligned}
$$

Estimated proportion of breast cancer patients you treat in your clinical practice in a month

$\square<10 \%$
$\square 10-25 \%$
$\square 26-50 \%$
$\square 51-75 \%$
$\square 75 \%+$




\section{Questionnaire: Understanding Current Attitudes to Her2 Testing}

1) In your opinion, should all women diagnosed with breast cancer be tested for Her2 at the point of diagnosis?

$\square$ yes

2) Refer to number 1, if answer is no, in your opinion on what basis (clinical or nonclinical) will women diagnosed with breast cancer be selected for Her2 testing?

$\square$ On the basis of type of carcinoma

$\square$ On the basis of fitness for systemic therapy

$\square$ Others. Please specify

3) Which of the following most accurately reflects the practices of Her2 testing at your center?

$\square$ Request all breast cancer patients Her2 testing at point of diagnosis

$\square$ Request breast cancer patients at advanced stage Her2 at point of diagnosis

$\square$ Request breast cancer patients of financial capability Her2 testing at point of diagnosis

$\square$ Request after chemotherapy and/ot hormone therapy failure and likely to be given trastuzumab

$\square$ Others. Please specify.

4) Which of the following currently represent the greatest barrier to initiating Her2 testing in your practice?

$\square$ Inadequate funds of patients

$\square$ Shortfall of adequate expertise/experience in Her2 testing

$\square$ Absence of local laboratory services with Her2 testing capability

$\square$ Absence of central laboratory services with Her2 testing capability

$\square$ Inadequate quality control and quality assurance for Her2 testing

5) In your opinion who should request Her2?

$\square$ Medical oncologist

$\square$ Surgeon

$\square$ Medical oncologist or surgeon, whoever sees patient first

$\square$ Pathologist

$\square$ Patient

6) In your opinion who should arrange for breast tissue sample collection

$\square$ Medical oncologist

$\square$ Surgeon

$\square$ Staff at operating theatre

$\square$ Pathologist

$\square$ Medical technician of histopathology lab

$\square$ Others. Please specify.

7) In your opinion, who should provide patients information about Her2 testing?

$\square$ Medical oncologist

$\square$ Surgeon

$\square$ Medical oncologist or surgeon, whoever sees patient first

$\square$ Nurses

$\square$ Others. Please specify. 